\title{
Cardiac constriction induced by fibrotic peel formation of myocardium due to polytetrafluoroethylene membrane
}

Dong Jin Kim, MD, Jae Gun Kwak, MD, and Woong-Han Kim, MD, PhD, Seoul, Korea

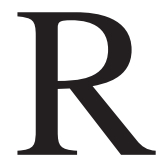
epeated operations are required for some cardiac diseases, and for safer reentry, a polytetrafluoroethylene (PTFE) membrane may be used. However, we experienced a fibrotic myocardial layer lying beneath a PTFE membrane, which constricted the heart and caused difficulty weaning the patient off cardiopulmonary bypass (CPB). After removing the fibrotic layer, the heart showed good contraction and weaning from CPB became possible. This case demonstrates that PTFE membrane placement may cause the formation of a fibrotic layer, which may adversely affect hemodynamics.

\section{Clinical Summary}

A 7-year-old boy was referred to our hospital for repair of a congenitally corrected transposition of great arteries (cc-TGA) with an intact ventricular septum. The patient had been diagnosed as having cc-TGA with progressive tricuspid valve regurgitation. He had undergone previous pulmonary artery banding (PAB) and $\mathrm{PAB}$ tightening for left ventricular (LV) training at 2 and 3 years of age, respectively.

The pressure gradient across the PAB was about $150 \mathrm{~mm} \mathrm{Hg}$ in echocardiography, and the morphologic LV (m-LV) pressure was suprasystemic by cardiac catheterization. LV wall motions were reduced, and overall ventricular function was poor. By cardiac magnetic resonance imaging, the $\mathrm{m}-\mathrm{LV}$ mass index was $53 \mathrm{~g} / \mathrm{m}^{2}$ and the morphologic right ventricular mass index was $52 \mathrm{~g} / \mathrm{m}^{2}$.

An operation was performed, and repeated sternotomy undertaken without difficulty due to a previously placed PTFE membrane $(0.1 \mathrm{~mm}$ thickness). The PAB was removed, and a double switch operation was performed (a Senning operation for atrioventricular discordance and an arterial switch operation for ventriculoarterial discordance). After finishing the main procedure, $\mathrm{CPB}$ weaning was difficult. When pump flow was reduced, transesophageal echocardiography (TEE) revealed poor m-LV contraction. We

From the Department of Thoracic and Cardiovascular Surgery, Clinical Research Institute, Seoul National University Children's Hospital, College of Medicine, Seoul National University, Seoul, Korea.

Received for publication Nov 5, 2006; accepted for publication Nov 20, 2006.

Address for reprints: Woong-Han Kim, MD, PhD, Department of Thoracic and Cardiovascular Surgery, Seoul National University, College of Medicine, Seoul National University Children's Hospital, 28 Yongon-Dong, Jongno-Gu, Seoul, 110-744, Korea (E-mail: woonghan@snu.ac.kr).

J Thorac Cardiovasc Surg 2007;133:843-4

$0022-5223 / \$ 32.00$

Copyright () 2007 by The American Association for Thoracic Surgery

doi:10.1016/j.jtcvs.2006.11.024 noted a fibrotic layer $7 \times 3 \mathrm{~cm}$ in size at the LV free wall, which had been formed by the PTFE membrane (Figure 1). This layer was removed; subsequently the free wall of the m-LV expanded markedly, and TEE revealed improved contraction. The patient was then weaned from CPB without difficulty. He was extubated on postoperative day 2 and remained in good condition until discharge.

\section{Discussion}

In this case it was difficult to decide on a double switch, because preoperative echocardiography showed poor ventricular function. However, a preoperative evaluation revealed a near-normal cardiac mass index and suprasystemic pressure of m-LV. Thus, it was assumed that removal of the tight band would reduce the afterload and cardiac function would be improved. However, after the main procedure, weaning from $\mathrm{CPB}$ proved impossible. This was resolved when the fibrotic layer was removed.

For repeated operation, PTFE membranes offer a good protective option. Bhatnagar et $\mathrm{al}^{1}$ evaluated safety of the PTFE surgical membranes in a prospective randomized trial. No significant differences were found between those with or without PTFE surgical membrane in terms of infection rate or mediastinal complications. Other studies suggested that closing the pericardium may adversely affect hemodynamics after open cardiac surgery. ${ }^{2-4} \mathrm{~A}$ loosely applied patch of biocompatible material, such as PTFE, was found to be suitable for pericardial closure and to prevent the adverse effects of primary pericardial closure during the early postoperative phase and the later development of a free dissection plane for any reoperation.

In the present case, it was noted that the PTFE membrane covering the myocardium caused formation of a fibrotic layer (Figure 2) and subsequent cardiac constriction. During the early

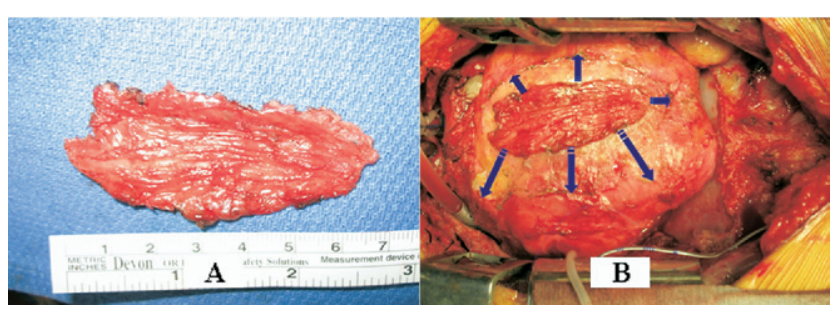

Figure 1. A, Excised fibrotic myocardial layer. B, Original position of excised fibrotic layer. The original margin was severely dilated. 


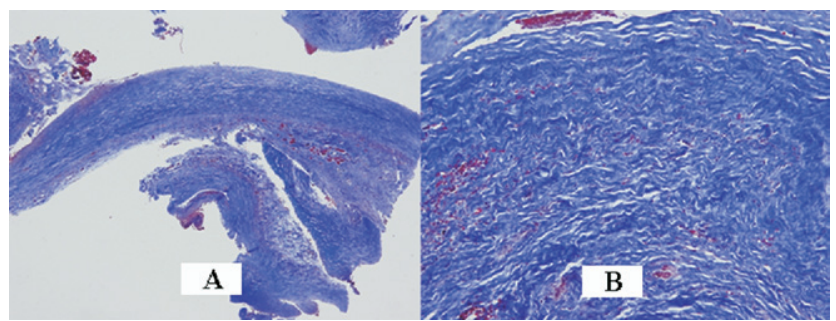

Figure 2. Pathologic examination of the excised fibrotic layer revealed dense fibrosis composed predominantly of fibrous tissue with mixed hyaline and sparse elastic connective tissue. Stained with Masson trichrome. A, magnification $\times 40$. B, magnification $\times 200$.

postoperative period, a PTFE membrane may have no effect on the cardiac function, but as demonstrated by the present case, later it can lead to cardiac constriction, which could be fatal if the patient concerned required a staged operation, especially when the PTFE membrane is positioned in a LV free wall such as with cc-TGA.

Randomized study of the effect of PTFE membranes on hemodynamics is required during the later postoperative period. We describe a case of cardiac constriction induced by a fibrotic layer that formed at the tissue-PTFE membrane interface, and we advocate caution when using PTFE membranes.

\section{References}

1. Bhatnagar G, Fremes SE, Christakis GT, Goldman BS. Early results using an ePTFE membrane for pericardial closure following coronary bypass grafting. J Card Surg. 1998;13:190-3.

2. Rao V, Komeda M, Weisel RD, Cohen G, Borger MA, David TE. Should the pericardium be closed routinely after heart operation? Ann Thorac Surg. 1999;67:484-8.

3. Daughters GT, Frist WH, Alderman EL, Derby GC, Ingels NB Jr, Miller DC. Effects of the pericardium on left ventricular diastolic filling and systolic performance early after cardiac operation. $J$ Thorac Cardiovasc Surg. 1992;104:1084-91.

4. Hunter S, Smith GH, Angelini GD. Adverse hemodynamic effects of pericardial closure soon after open heart operation. Ann Thorac Surg. 1992;53:425-9. 